\title{
Back to Basics: Improving Care for Psychosis
}

\section{Sandra Steingard ${ }^{1}$}

Published online: 6 June 2020

(c) Springer Science+Business Media, LLC, part of Springer Nature 2020
I write this on a beautiful day that belies the ongoing struggles and uncertainties we are all facing amidst the COVID19 pandemic. The Journal is receiving numerous submissions on matters related to the pandemic, including its impact on mental wellbeing and approaches to service delivery. Those of us who do clinical work have already experienced a remarkably swift transition to working by phone and/or video and the convenience of this way of operating makes it hard to envision a full return to previous practices. I am nearing the end of my clinical career so I will not participate in the further evolution of these changes, however, in my work as a journal editor, I hope to foster a place for sharing innovative strategies to address the future needs of our communities.

This month's Journal, however, focuses on what I have always considered a core topic of community mental health and the subject that drew me to this line of work, namely, the care of people who experience psychosis. It is the nature of journal publishing that many of articles in this issue were submitted — and some even accepted-before my tenure as editor-in-chief began. But it is the prerogative of the editor to choose not only which articles are accepted but when they are published and I found it fitting to publish, in the waning moments of my clinical career, an edition that addresses the topic that captured and held my attention for so many years.

This issue includes articles on the phenomenology of psychosis from both professional and personal perspectives, family experiences, rehabilitative practices, and development of peer specialists. We also have papers on food insecurity and the benefits of physical activity.

One article that is of particular salience for me is the paper by Wusinich et al. (2020) on the Parachute NYC project. This was an innovative program that was based on the concepts of need-adapted treatment (NAT), a forerunner of Open Dialogue. The article reports a qualitative study in

Sandra Steingard

SandyS@howardcenter.org

1 Howard Center, Burlington, VT 05401, USA which participants in the program-individuals and their families-were interviewed and major themes were identified. It contributes to the growing worldwide interest in this way of working.

I was drawn to NAT almost 10 years ago, when I learned of practitioners' reports of excellent outcomes while using antipsychotic drugs in a limited way. As I studied it further, I learned that there was much more to this work than their use of medication. NAT came about from recognition that there was no "best" way to conceptualize psychosis. In the late 1980s, there were many explanatory theories-biological, psychological, social—each of which was attached to a particular type of treatment, any one of which appeared to be helpful for some people and not for others. Clinicians working in psychiatric hospitals in Finland found that having discussions with patients and their families about this dilemma appeared to be of benefit. They focused their attention away from studying the efficacy of each treatment and toward an understanding of the therapeutic effects of these meetings. From that emerged NAT.

A core feature of NAT is its democratic way of working. The psychiatrist is not considered to be the only expert in the room-other professionals, as well as family members and the patient-are thought to have valuable perspectives and opinions. In addition, the team considers uncertainty a virtue. Rather than prioritizing the need to establish a diagnosis, this approach acknowledges that these problems are complex and that it often takes time to derive understandings of them.

As one reads in the article, this uncertainty was not always welcome by the network but I argue that it can enhance psychiatric practice. Uncertainty and humility are values that can enrich rather than diminish psychiatric practice in the months and years ahead. I look forward to continuing to explore what we do not know and to seek edification in the pages of this journal. 


\section{Reference}

Wusinich, C., Lindy, D. C., Russell, D., et al. (2020). Experiences of parachute NYC: An integration of open dialogue and intentional peer support. Community Mental Health Journal https:// doi.org/10.1007/s10597-020-00556-0
Publisher's Note Springer Nature remains neutral with regard to jurisdictional claims in published maps and institutional affiliations. 